\title{
How to Deal with Cervical Tooth Sensitivity (Review)
}

\author{
Waseem Mohamed Alsaydali ${ }^{1}$ Ahmed Mohamed Elmarakby ${ }^{2,3 *}$, Mohammed Jamal Alkhanani ${ }^{1}$ and Abdulmohsen \\ Saleh Alghabban ${ }^{1}$ \\ ${ }^{1}$ Dental Intern at, Alfarabi Colleges for Dentistry and Nursing, Saudi Arabia
}

${ }^{2}$ Assistant Professor at Restorative Dentistry, Al-Farabi Colleges for Dentistry \& Nursing Riyadh, Saudi Arabia

${ }^{3}$ Lecturer of Operative Dentistry, Faculty of Dentistry, Al-Azhar University, Egypt

*Corresponding author: Ahmed Mohamed Elmarakby, Assistant Professor at Restorative Dentistry, Al-Farabi Colleges for Dentistry \& Nursing and Lecturer of Operative Dentistry, Faculty of Dentistry, Al-Azhar University, Assiut Branch, Egypt

Submission: 眥 July 22, 2017; Published: 盟 October 03, 2017

\begin{abstract}
The objective of this review is to inform practitioners about dentin hypersensitivity (DH); to provide a brief overview of the diagnosis, etiology and clinical management of dentin hypersensitivity and to discuss technical approaches to relieve sensitivity. This clinical information is described in the context of the underlying biology. The author used PUBMED to find relevant English-language literature published in the period 2000 to 2015. The author used combinations of the search terms "dentin*”, "tooth", "teeth", "hypersensit*”, "desensitiz*”. Abstracts and also full text articles to identify studies describing etiology, prevalence, clinical features, controlled clinical trials of treatments and relevant laboratory research on mechanisms of action were used.
\end{abstract}

\section{Introduction}

A common question asked by dentists is how to deal with cervical tooth sensitivity. Practitioners are commonly confronted with patients who complain about cervical sensitivity, but unfortunately, those patients seldom receive adequate relief. The minor discomfort is often considered too minimal to warrant significant time on the dentist's part, and very few practitioners have delegated tooth desensitization to auxiliary personnel [1-3].

This article explores major causes of cervical tooth sensitivity, describes products and techniques for reduction or elimination of this annoying challenge, and encourages use of dental auxiliaries to provide tooth desensitization procedures.

\section{Major Reasons for Cervical Tooth Sensitivity \\ Gingival recession}

Gingival recession is usually expected as a person ages; however, it might also be caused by traumatic conditions [4,5]. It is impossible to avoid lifelong apical migration of tooth-supporting tissues. As gingiva recedes, cementum surfaces become denuded and dentin is exposed [6-8]. Depending on the patient's age, dentinal canals might be large and wide open, allowing easy access of mouth fluids, food debris and microorganisms, or they might be small and nearly occluded. Occurrence of sensitivity of these surfaces is difficult to predict $[9,10]$. While some patients complain of sensitivity with only minor gingival recession, others appear to have no sensitivity with major gingival apical migration and exposed dentin [11-13] (Figure 1).

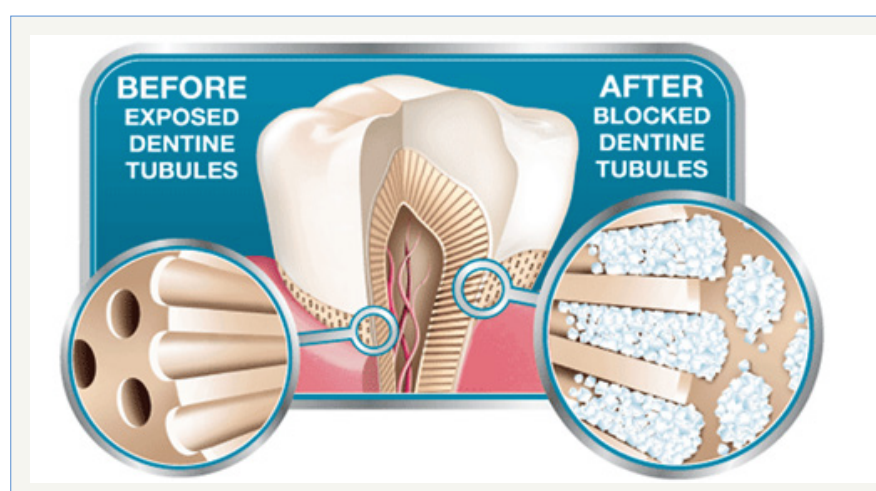

Figure 1: Showing the reason of dentin hypersensitivity due to open dentinal tubule then desensitization after blockage of the tubules.

\section{Certain beverages}

Soft drinks and other acidic beverages are consumed in large volumes by many people. It is not uncommon for some people to carry refillable containers in their cars with some form of acidic drink available nearly all of the time. Both sugar-containing and socalled "diet" soft drink beverages have a low pH. Consumption of several 12-ounce containers of soft drinks per day is not uncommon, especially among young adults [13-16]. Tooth demineralization 
is unavoidable under these conditions. When patients complain of cervical tooth sensitivity, they should be questioned about excessive consumption of soft drinks, low-pH fruit juices or other similar drinks. If they are consuming low-pH drinks in excess, they should be advised to reduce the amount consumed and to rinse their mouths with water after drinking the low-pH solutions [1720] (Figure 2).

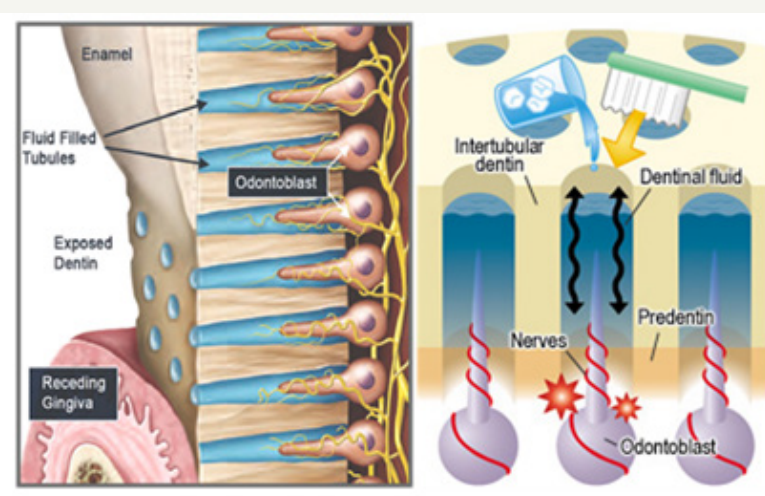

Figure 2: Showing diagrammatic appearance resemble what seen under SEM to reveal the cause of dentine hypersensitivity due to fluid movement theory.

\section{Bulimia}

Bulimia is a common malady in which thousands of people, mainly girls and women, attempt to reduce or control their weight by vomiting, sometimes several times per day. Tooth enamel is dissolved very rapidly by the resultant constant low-pH oral condition. Bulimics can have severe tooth sensitivity to the degree that even the slight temperature change caused by alginate impressions is intolerable. If bulimiais suspected, as evidenced by significant enamel destruction on the lingual surfaces of upper anterior and upper molar teeth, psychological treatment of patients should be sought immediately. Lack of treatment for bulimic patients often results in dire physical conditions and even death (21-23).

\section{Sugar}

Sugar-containing objects in the mouth, such as breath candies, chewing tobacco and gum, are often placed in the same oral location frequently. Their sugar content, combined with oral debris, soon initiates tooth demineralization, sensitivity and caries, especially in Class V areas. People using these products are easily identified, due to localized tooth sensitivity or dental caries, and they should be advised to avoid these destructive practices [24,25].

\section{Pyrophosphates}

Tartar-control toothpastes containing pyrophosphates cause cervical tooth sensitivity in a small percentage of people. When cervical sensitivity persists, patients should be advised to avoid all toothpastes for at least two weeks, using only toothbrush and floss for oral hygiene, to see if elimination of pyrophosphate reduces sensitivity. If sensitivity is reduced, toothpastes not containing pyrophosphates should be used by these people (26-29).

\section{Abusive tooth-brushing}

Abusive tooth-brushing habits are easily observed. Patients should be advised about the necessity to eliminate abusive toothbrushing habits as soon as they can be observed by dentists or dental hygienist [30].

\section{Products and Techniques for Reduction or Elimination of Cervical Sensitivity}

a) Reduce or remove the offending factors described previously.

It is foolish to initiate clinical techniques to reduce tooth sensitivity if patients can accomplish the desensitization without any therapeutic procedures [31].

b) Place the patient on a regimen of highly fluoridated dentifrices, the most well-known of which is (Colgate Prevident 5000), a specially introduced prescription dentifrice containing 5,000 parts per million fluoride. This toothpaste is also highly effective in preventing dental caries, as it contains five times more fluoride than most over-the-counter toothpastes [32].

c) Have the patient use one or more of the over-the-counter tooth-desensitizing toothpastes. Numerous types are on the market. They contain low concentrations of various chemicals. Unfortunately, these toothpastes are weaker than is desirable, allowing them to be dispensed over the counter without a prescription. As a result, their therapeutic value is less than what is possible. Nevertheless, they give patients something to use, and in combination with reduction of tooth sensitizing habits, they could reduce tooth sensitivity $[33,34]$.

d) Use of conventional dentin bonding agents is the most commonly performed clinical procedure for cervical tooth sensitivity. Clinical techniques for desensitization are simple and can be delegated easily to competent, educated, responsible auxiliaries in accordance with the dentist's diagnosis and treatment plan. A typical technique follows: Anesthetize the affected teeth; place gingival retraction cord to reduce periodontal fluid flow; clean teeth well with flour of pumice slurry; place your most used dentin-bonding agent, as all of these products accomplish essentially the same purpose: obturation and sealing of dentinal canals. (Popular, effective products are Amalgam bond, Parkell; Single Bond, 3M Dental Products Division; Prime \& Bond, Dentsply/ Caulk; Optibond, Kerr Corp.; and One-Step, Bisco.) Limit the placement of these materials to the tooth areas that were sensitive to explorer touch. Do not "pool" the bonding agents. If bonding resins are pooled, patients can pull them off when flossing, and they feel rough to the tongue. Place only thin coats in multiple applications [35-37].

e) Use of iontophoresis is an effective desensitization procedure that should be employed more often. Typical desensitizing iontophoresis devices are the Desensitron by Parkell and the Iontophoresis Instrument by Hampton 
Research. These instruments allow delivery of provided fluoride into dentin tooth surfaces by the electrical phenomenon of iontophoresis [38-41].

Desensitization by iontophoresis can be accomplished in place of other procedures, or the technique can be used before the placement of a bonding agent $[42,43]$. The most effective procedure for eliminating cervical tooth sensitivity is iontophoresis followed by placement of bonding agent. All desensitization procedures described in this article can be accomplished easily by dental auxiliaries. Desensitization is a technique well-accepted by patients [44-46].

Desensitization of teeth is one of many procedures that can be delegated to auxiliary personnel successfully, stimulating them to further professional achievement and satisfaction with their clinical activities [47]

\section{Conclusion}

One of the most perplexing minor tooth maladies is cervical tooth sensitivity. After personal habits that encourage tooth sensitivity are reduced or eliminated, numerous clinical procedures can be used to control remaining tooth sensitivity well.

\section{References}

1. Orchardson R, Gillam DG (2006) Managing dentin hypersensitivity. J Am Dent Assoc 137(7): 990-998,

2. Porto IC, Andrade AK, Montes MA (2009) Diagnosis and treatment of dentinal hypersensitivity. J Oral Sci 51(3): 323-332.

3. Miglani S, Aggarwal V, Ahuja B (2010) Dentin hypersensitivity: Recent trends in management. J Conserv Dent 13(4): 218-224.

4. Canadian Advisory Board on Dentin Hypersensitivity (2003) Consensusbased recommendations for the diagnosis and management of dentin hypersensitivity. J Can Dent Assoc 69(4): 221-226.

5. Aranha AC, Pimenta LA, Marchi GM (2009) Clinical evaluation of desensitizing treatments for cervical dentin hypersensitivity. Braz Oral Res 23(3): 333-339.

6. Chu CH, Lo ECM (2010) Dentin hypersensitivity: a review. Hong Kong Dent J 7: 15-22.

7. Bartlett DW, Shah PA (2006) Critical review of non-carious cervical (wear) lesions and the role of abfraction, erosion, and abrasion. J Dent Res 85(4): 306-312.

8. Que K, Guo B, Jia Z, Chen Z, Yang J, et al. (2013) Cross sectional study: non-carious cervical lesions, cervical dentine hypersensitivity and related risk factors. J Oral Rehabil 40(1): 24-32.

9. Cummins D (2010) Recent advances in dentin hypersensitivity: clinically proven treatments for instant and lasting sensitivity relief. Am J Dent 23 Spec No A: 3A-13A.

10. Fischer C, Fischer RG, Wennberg A (1992) Prevalence and distribution of cervical dentine hypersensitivity in a population in Rio de Janeiro, Brazil. J Dent 20(5): 272-276.

11.Cummins D (2009) Dentin hypersensitivity: from diagnosis to a breakthrough therapy for everyday sensitivity relief. J Clin Dent 20(1): $1-9$.

12.Gillam DG, Bulman JS, Eijkman MA, Newman HN (2002) Dentists' perceptions of dentine hypersensitivity and knowledge of its treatment. J Oral Rehabil 29(3): 219-225.
13. Addy M (2000) Dentine hypersensitivity: Definition, prevalence, distribution and etiology. In: Addy M, Embery G, Edgar WM, Orchardson $\mathrm{R}$ (Eds.), Tooth wear and sensitivity: Clinical advances in restorative dentistry. Martin Dunitz, London, pp. 239-248.

14.Gillam DG, Seo HS, Bulman JS, Newman HN (1999) Perceptions of dentine hypersensitivity in a general practice population. J Oral Rehabil 26(9): 710-714.

15. Roberson T, Heymann HO, Swift EJ (2006) Sturdevant's art and science of operative dentistry. ( $6^{\text {th }}$ edn), Mosby, Canada, pp. 6-10.

16. Dababneh RH, Khouri AT, Addy M (1999) Dentine hypersensitivityan enigma? A review of terminology, mechanisms, aetiology and management. Br Dent J 187(11): 606-611.

17. Borges A, Barcellos D, Gomes C (2012) Dentin hypersensitivity- etiology, treatment possibilities and other related factors: a literature review. World Journal of Dentistry 3(1): 60-67.

18. Lussi A (2006) Dental erosion: from diagnosis to therapy. Basel Karger 20: $173-190$.

19.Zero DT, Lussi A (2005) Erosion-chemical and biological factors of importance to the dental practitioner. Int Dent J 55(4): 285-290.

20. Addy M, Mostafa P, Newcombe RG (1987) Dentine hypersensitivity: the distribution of recession, sensitivity and plaque. J Dent 15(6): 242-248.

21. Braennstrom M, Astroem A (1964) A study on the mechanism of pain elicited from the dentin. J Dent Res 43: 619-625.

22. Cunha-Cruz J, Wataha JC, Zhou L, Manning W, Trantow M, et al. (2010) Treating dentin hypersensitivity: therapeutic choices made by dentists of the northwest PRECEDENT network. J Am Dent Assoc 141(9): 10971105.

23. Minoux M, Serfaty R (2008) Vital tooth bleaching: biologic adverse effects-a review. Quintessence Int 39(8): 645-659.

24.Gillam DG, Orchardson R (2006) Advances in the treatment of root dentine sensitivity-mechanisms and treatment principles. Endodontic Topics 13(1): 13-33.

25. Suge T, Kawasaki A, Ishikawa K, Matsuo T, Ebisu S (2006) Effects of plaque control on the patency of dentinal tubules: an in vivo study in beagle dogs. J Periodontol 77(3): 454-459.

26. Eisenburger M, Addy M (2002) Erosion and attrition of human enamel in vitro part I: interaction effects. J Dent 30(7-8): 341-347.

27. Mayhew RB, Jessee SA, Martin RE (1998) Association of occlusal, periodontal, and dietary factors with the presence of non-carious cervical dental lesions. Am J Dent 11(1): 29-32.

28. von Troil B, Needleman I, Sanz M (2002) A systematic review of the prevalence of root sensitivity following periodontal therapy. J ClinPeriodontol 29(3): 173-177.

29. Grossman L (1935) A systematic method for the treatment of hypersensitive dentine. J Am Dent Assoc 22(4): 592-602.

30. Peacock JM, Orchardson R (1995) Effects of potassium ions on action potential conduction in A and C fibers of rat spinal nerves. J Dent Res 74(2): 634-641.

31. Poulsen S, Errboe M, Lescay Mevil Y, Glenny AM (2006) Potassium containing toothpastes for dentine hypersensitivity. Cochrane Database Syst Rev 19(3): CD001476.

32. Sowinski JA, Battista GW, Petrone ME, Chaknis P, Zhang YP, et al. (2000) A new desensitizing dentifrice an 8-week clinical investigation. Compend Contin Educ Dent Suppl 27(11): 11-16.

33. Markowitz K (2013) A new treatment alternative for sensitive teeth: a desensitizing oral rinse. J Dent 41(1): S1-S11.

34. Walters PA (2005) Dentinal hypersensitivity: a review. J Contemp Dent Pract 6(2): 107-117. 
35. Morris MF, Davis RD, Richardson BW (1999) Clinical efficacy of two dentin desensitizing agents. Am J Dent 12(2): 72-76.

36. Pillon FL, Romani IG, Schmidt ER (2004) Effect of a 3\% potassium oxalate topical application on dentinal hypersensitivity after subgingival scaling and root planing. J Periodontol 75(11): 1461-1464.

37. Vieira AH, Passos VF, de Assis JS, Mendonça JS, Santiago SL (2009) Clinical evaluation of a $3 \%$ potassium oxalate gel and a GaAlAs laser for the treatment of dentinal hypersensitivity. Photomed Laser Surg 27(5): 807-812.

38. Sauro S, Gandolfi MG, Prati C, Mongiorgi R (2006) Oxalate containing phytocomplexes as dentine desensitisers: an in vitro study. Arch Oral Biol 51(8): 655-664.

39. Lee Y, Chung WG (2011) Management of dentin hypersensitivity. J Korean Academy Endodontics 12: 16.

40. Hack GD, Thompson VP (1994) Occlusion of dentinal tubules with cavity varnishes. Archs Oral Biol 39: S149.

41. Duran I, Sengun A (2004) The long-term effectiveness of five current desensitizing products on cervical dentine sensitivity. J Oral Rehabil 31(4): 351-356.
42.Holland GR, Narhi MN, Addy M, Gangarosa L, Orchardson R (1997) Guidelines for the design and conduct of clinical trials on dentine hypersensitivity. J ClinPeriodontol 24(11): 808-813.

43. Dondidall'Orologio G, Lone A, Finger WJ (2002) Clinical evaluation of the role of glutardialdehyde in a one bottle adhesive. Am J Dent 15(5): 330-334.

44.Hench LL, Splinter RJ, Allen WC, Greenlee TK (1971) Bonding mechanisms at the interface of ceramic prosthetic materials. J Biomed Mater Res 5(6): 117-141.

45. Forsback AP, Areva S, Salonen JI (2004) Mineralization of dentin induced by treatment with bioactive glass S53P4 in vitro. Acta Odontol Scand 62(1): $14-20$

46. Vollenweider M, Brunner TJ, Knecht S, Grass RN, Zehnder M, et al. (2007) Remineralization of human dentin using ultrafine bioactive glass particles. Acta Biomater 3(6): 936-943.

47.Cai F, Shen P, Morgan MV, Reynolds EC (2003) Remineralization of enamel subsurface lesions in situ by sugar free lozenges containing casein phosphopeptide-amorphous calcium phosphate. Aust Dent J 48(8): $240-243$ 